\title{
Colegaje médico
}

\author{
José María Maya ${ }^{1}$
}

\section{RESUMEN}

Se presenta un caso de evento adverso prevenible, en una paciente gestante en proceso de parto, que es atendida por un obstetra alicorado, lo que causa la caída del neonato en el momento del parto. El anestesiólogo, a solicitud del obstetra, decide no reportar el evento adverso y solicita a la enfermera profesional guardar silencio al respecto. Ante la negativa de esta y su recriminación, el anestesiólogo defiende su actuación, argumentación que obedece al colegaje médico que debe practicar. Se realiza un análisis del caso aclarando el sentido y alcance de esta figura.

PALABRAS CLAVE: ética profesional; colegaje médico; evento adverso.

\section{MEDICAL COLLEGE}

\section{SUMMARY}

Presentation of a case of preventable adverse event in a pregnant patient in the process of childbirth, which is attended by a twitching obstetrician, causing the newborn to fall at the time of delivery. The anesthesiologist at the request of the obstetrician decides not to report the adverse event and asks the professional nurse to keep silent about it. Before the refusal of this and its recrimination, the anesthesiologist defends his performance, the argument that obeys the medical association that he must practice. The case analysis is carried out clarifying the meaning and scope of this figure.

KEY WORDS: Professional ethics; Medical partnership; Adverse event.

1. Médico, magister en Salud Pública, magister en Dirección Universitaria y magister en Dirección y Gestión de la Seguridad Social; profesor titular, Universidad CES; decano general, Escuela de Ciencias de la Vida. Universidad EIA, Medellín, Colombia. ORCID https://orcid.org/oooo-0003-3721-7572

Correspondencia: José María Maya; email: josemariamayamejia@gmail.com

Recibido: $17 / 04 / 20$; aceptado: $18 / 04 / 20$

Cómo citar: Maya JM. Colegaje médico. Rev Asoc Colomb Dermatol. 2020;28(1):15-16. DOI: https://doi.org/10.29176/2590843X.1486

Financiación: ninguna, conflictos de interés: ninguno 


\section{PRESENTACIÓN DEL CASO DE ÉTICA NO 11}

Una paciente de 28 años ( $\mathrm{G}_{2} \mathrm{P} 1 \mathrm{Ao}$ ), con un embarazo de 38 semanas de gestación, acude al servicio de urgencias de una institución de tercer nivel de atención, por presentar trabajo de parto. El médico que atiende el servicio de urgencias, luego de verificar que el trabajo de parto está avanzado, le pregunta a la paciente por el nombre del obstetra que ha realizado el control prenatal y atenderá el parto; decide llamarlo, a pesar de que es sábado y son las 2 de la mañana. El obstetra, después de dialogar con el médico de urgencias y ante la inminencia del parto, acepta trasladarse a la institución para su atención. Al llegar a la IPS, le informan que la paciente fue transferida a sala de parto para la aplicación de la anestesia raquídea. Cuando el médico obstetra ingresa a la sala, el anestesiólogo que aplica la anestesia percibe que su colega obstetra se encuentra en un alto grado de alicoramiento, por lo cual le sugiere llamar al obstetra de turno presencial en la institución para que realice la atención del parto. El obstetra se niega a que se llame al colega de turno alegando que él se encuentra en buen estado y puede atenderlo. El anestesiólogo no insiste y acepta. En el momento del expulsivo, el obstetra siente mareo a causa del consumo de alcohol y es incapaz de recibir adecuadamente al neonato, que se desprende bruscamente del canal del parto, cae y se golpea contra el piso de la sala. El anestesiólogo y la enfermera profesional acuden a socorrer al recién nacido y terminan de atender el parto ante la imposibilidad del obstetra para llevarlo a cabo. La paciente no es claramente consciente de lo sucedido. El anestesiólogo pide al pediatra de turno revisar al niño y este no encuentra lesiones graves evidentes, excepto una escoriación en la frente como consecuencia del golpe. El anestesiólogo que atiende la solicitud del colega obstetra decide no reportar el evento adverso prevenible y le solicita a la enfermera profesional que guarde silencio al respecto. La enfermera se muestra en desacuerdo con la solicitud del obstetra, aceptada por el anestesiólogo, y manifiesta que hará el reporte respectivo del evento adverso, que era perfectamente prevenible si el parto hubiera sido atendido por un obstetra en condiciones adecuadas para hacerlo. Recrimina al anestesiólogo por haber aceptado que el obstetra alicorado atendiera el parto, poniendo en riesgo a la paciente y su nuevo hijo, y no haber solicitado la ayuda del obstetra de turno presencial de la institución. El anestesiólogo se defiende argumentado que, por colegaje médico, él debe proteger al colega y evitar que lo sancionen.

\section{CUESTIONAMIENTOS ÉTICOS}

1. Describa algunas características del colegaje médico.

2. Analice el comportamiento de los tres profesionales de la salud: médico ginecoobstetra, médico anestesiólogo y enfermera profesional.

3. ¿Cuáles son los límites del colegaje médico?

\section{Puntos clave}

- $\quad$ Concepto y alcance de colegaje profesional

- $\quad$ Evento adverso prevenible

\section{Ética continúa en la página 90}

